\title{
Surgical Management of Fracture Neck of Femur in a Medically Unfit ASA3/4 Patient Selection Using Direct Infiltration Local Anaesthesia
}

\author{
Tamer Kamal1,2, Sunil Garg3, Kareem Elsorafy4, Anca Duca1 \\ ${ }^{1}$ Robert Jones and Agnes Hunt Orthopaedic Hospital, Oswestry, UK \\ ${ }^{2}$ Orthopaedic Department, Cairo University, Cairo, Egypt \\ ${ }^{3}$ James Paget University Hospital NHS Foundation Trust, Great Yarmouth, UK \\ ${ }^{4}$ Department of Trauma, Orthopaedics Leicester Royal Infirmary, Leicester, UK \\ Email: tamerkamal@yahoo.com
}

Received 27 May 2014; revised 12 July 2014; accepted 26 July 2014

Copyright (C) 2014 by authors and Scientific Research Publishing Inc.

This work is licensed under the Creative Commons Attribution International License (CC BY). http://creativecommons.org/licenses/by/4.0/

\section{(c) (i) Open Access}

\begin{abstract}
Patients who suffer a Fractured Neck of Femur (NOF) have a high mortality and morbidity rate with up to $20 \%$ needing long term care post fracture and a further $30 \%$ not returning to their pre fracture functioning. Hip fracture accounts for $87 \%$ of total fragility fractures. We describe an anaesthetic technique of fixation of fracture of the femoral neck under direct infiltration local anaesthesia; that can be performed on the sick elderly patient. Twenty-eight NOF fractures were included in this series (24 DHS, 4 Hemiarthroplasty); twenty-three procedures were completed (82.14\%); no patient required conversion to another form of anaesthesia either general or spinal; five patients required some degree of light sedation due to agitation $(17.8 \%)$. This method presents itself as an option in managing patient with high comorbidities which can also be implemented in impoverished areas with limited access to operating surgical facilities.
\end{abstract}

\section{Keywords}

Fracture Neck of Femur, Local Infiltration, ASA4

\section{Introduction}

A major increase in hip fracture worldwide is directly related to the increase in aging population. Fracture of

How to cite this paper: Kamal, T., Garg, S., Elsorafy, K. and Duca, A. (2014) Surgical Management of Fracture Neck of Femur in a Medically Unfit ASA3/4 Patient Selection Using Direct Infiltration Local Anaesthesia. Open Journal of Orthopedics, 4, 195-199. http://dx.doi.org/10.4236/ojo.2014.48032 
neck of femur is a significant cause of morbidity and mortality. Patients who are considered fit usually undergo internal fixation or hemiarthroplasty of the hip aiming at early mobilisation and minimising the risk of long term bed rest. Patients who are considered too unwell for surgery are often delayed until assumed optimised or treated non-operatively [1]-[3]. The current fracture neck of femur guidelines provides strict rules emphasising early surgery within 24 - 48 hours of admission with early ortho-geriatric input. Failure to achieve these goals leads higher risk of patient mortality and morbidity and financial penalties to be incurred by hospitals. We describe an anaesthetic technique of fixation of fracture of the femoral neck under direct infiltration local anaesthesia; that can be performed on the sick elderly patient with low risk association than with general or regional anaesthesia which can also be implemented in impoverished areas with limited access to operating surgical facilities.

Consent and Ethical committee approval:

Patient informed consent and departmental ethical committee approval was acquired.

\section{Method}

The anaesthetic procedure was carried out by one senior consultant anaesthetist in all cases. Prior to surgery informed consent was obtained and pain scores were provided by patients prior and after local infiltration and intraoperatively. The maximum dose of local anaesthetic agent was calculated as follows:

- Maximum dose of lignocaine without adrenaline is $3 \mathrm{mg} / \mathrm{kg}$.

- Maximum dose of lignocaine with adrenaline is $7 \mathrm{mg} / \mathrm{kg}$.

- Marcaine up to $225 \mathrm{mg}$ with epinephrine 1:200,000 and $175 \mathrm{mg}$ without epinephrine.

Maximum dosage limit must be individualized in each case after evaluating the size and physical status of the patient, however a mixture of $20 \mathrm{ml}$ normal saline $+20 \mathrm{ml}$ of $1 \%$ lignocaine with 1:200,000 adrenaline $+20 \mathrm{ml}$ of $0.25 \%$ plain Marcaine was used in $78 \%$ of cases (22 patients) without the need for further local anaesthetic administration. In the remaining group (6 patients), an extra administration was required of the previous mixture making sure not to exceed maximum dosage per individual patient.

Anatomical landmarks were highlighted and marked including femoral artery, anterior superior iliac spine, inguinal ligament, femoral neck and surgical incision. Infiltration is carried out first $1 \mathrm{~cm}$ lateral to femoral artery (femoral nerve block) and along the inguinal crease. Aspirate to avoid intravascular injection, before injecting deep and lateral to the femoral artery. Pushing the needle through, two layers of resistance (fascia lata and fascia iliaca) should be felt; then pull back slightly to inject: in a fan like motion around the femoral nerve. (Figure 1) This followed by infiltration along the course of lateral cutaneous nerve of the thigh just distal to inguinal ligament close to ASIS (Figure 2), and injection along the surgical incision area, around the femoral neck and into the capsule of the hip joint (Figure 3 and Figure 4).

Patients with extra capsular fracture neck of femur were placed supine on traction table and fracture reduced pre-operatively. Fixation was carried using Dynamic Hip and Screw fixation (DHS), while intra-capsular neck of femur patients were placed in lateral decubitus position. A modified Hardings approach was used and uncemented prosthesis were used.

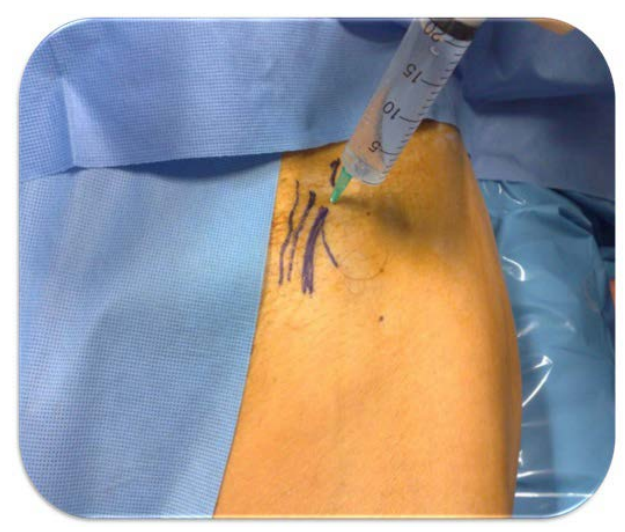

Figure 1. Identification of femoral artery and infiltration around femoral nerve. 


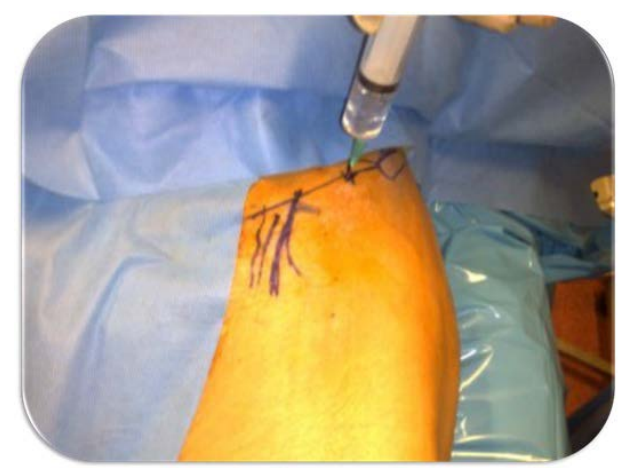

Figure 2. Infiltration for lateral cutaneous nerve of the thigh.

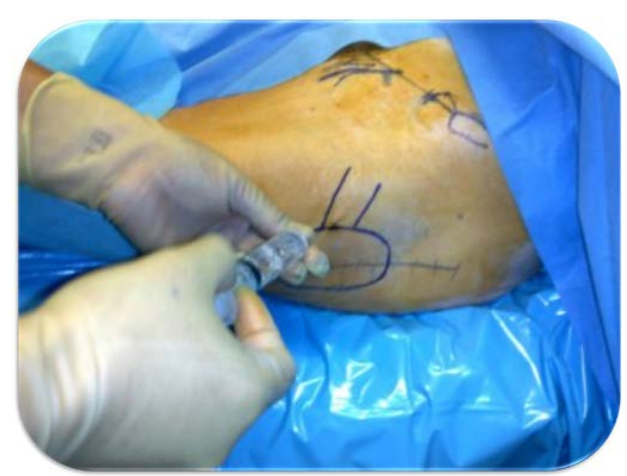

Figure 3. Infiltration for superior margin of the neck.

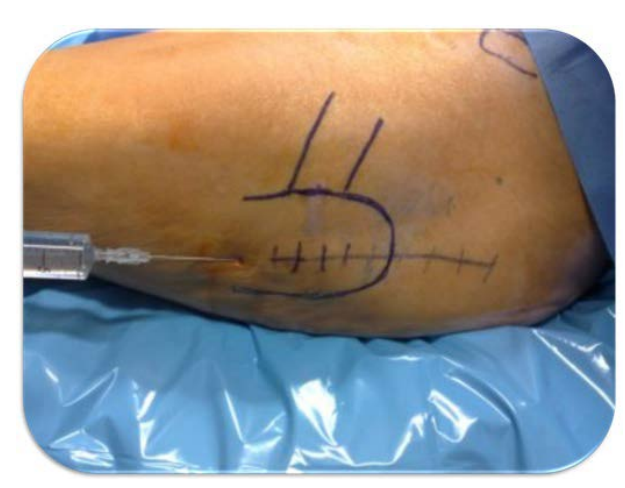

Figure 4. Infiltration along surgical incision.

\section{Results}

A total of twenty-eight ASA 3/4 patients were included in this series between June 2008 and December 2009 at Darent valley hospital. Departmental ethical committee approval was acquired prior to this study. Patient comorbidities, mini-mental scoring, intra-operative pain scores, operative time and bleeding were recorded.

All patients were operated by senior registrars under direct supervision of senior consultants as per nice guidelines recommendations (at time). Twenty-four (24) DHS and four (4) hemiarthroplasties were performed using this technique. Patients with Mini-Mental Score (MMS) less than 7 were excluded from this study. The procedure was completed successfully on 23 patients using this technique (82.14\%); no patient required conversion to another form of anaesthesia either general or spinal. Five patients required some degree of light sedation due to agitation (17.8\%). The average duration of surgery was $51.5 \mathrm{~min}$ (32 - 70 minutes). Average intra-operative blood loss was $370 \mathrm{ml}$ (200 - 650). The mean intra-operative pain score was 2.6/10 using visual analogue scor- 
ing system (VAS). 7 patients (30.4\%) described the procedure as excellent, 11 patients as satisfactory (47.8\%) two as good (8.7\%) and 3 as poor (13.1\%). All patients survived the procedure until discharge form hospital. Patients were allowed to mobilise freely after the procedure. No further follow-up was carried out after discharge period.

\section{Discussion}

Direct application of local anaesthetic to wounds can provide analgesia through two different mechanisms. It is widely accepted that local anaesthetics directly block transmission of pain from nociceptive afferents in the wound surface. By binding to fast sodium channels within the axon membrane, propagation of the action potential is prevented. Local anaesthetics can also inhibit the local inflammatory response to injury, which normally sensitizes nociceptive receptors and contributes to pain and hyperalgesia. Local anaesthetic infiltration reduces the release of inflammatory mediators from neutrophils, reduces neutrophil adhesion to the endothelium, reduces formation of free oxygen radicals, and decreases oedema formation.

The sensory innervation of the femoral neck is not clear. Hilton's law states that the sensory supply to a joint is derived from the nerves to the muscles acting across that joint [13]. This would suggest that nociception from a fracture of the femoral neck is mediated via the obturator, sciatic and femoral nerves and that a femoral nerve block would reduce, but not abolish, the pain from any fracture in this region. The femoral nerve block has wide applications, yet it is infrequently used [4] [12] [14] [15]. Techniques may vary slightly but principles are the same. Vloka et al. (1999)'s study on cadavers concluded that $1 \mathrm{~cm}$ lateral to femoral artery along the inguinal crease (and not inguinal ligament) was a safer location to inject to avoid hitting femoral nerve [5].

Finlayson \& Underhill (1988) discussed a method of anaesthetic for femoral neck surgery using a femoral nerve block at the level of the inguinal ligament. Local anaesthetic was injected around the femoral nerve, around but not inside the femoral artery, as well as taking care to avoid the joint itself, together with light sedation, patients were sufficiently anesthetized for fracture reduction [8] [9]. The technique allowed fractures to be repaired on patients too frail for general anaesthesia or spinal/epidural anaesthesia [7] [9]. Underhill also noted that all 16 patients with extra capsular fractures in the study had reduction of pain compared to only 14 out of 20 intracapsular fracture patients; the femoral nerve block is probably more effective on extra capsular fractures [6] [8].

Howard et al. (1983) used a femoral nerve block technique in combination with low dose intravenous ketamine and diazepam, they were able to internally fix subcapital fractures of the femur. Auliffe \& Harmon (2009) [15] describe a technique of anaesthesia in fractured neck of femur patients by injecting local anaesthetic (10 ml $0.5 \%$ levobupivucaine) directly into the fracture with ultrasound guidance. They suggested it may be sufficient for fracture reduction and in elderly patients awaiting surgery. Sher and Biant (2007) reported using a technique of direct infiltration of local anaesthetic at the surgical site rather than targeting any particular peripheral nerve(s), but on a number of small nerves close to the surgical site; they were able to repair femoral neck fractures without the use of general anaesthesia, the technique allowed surgical fixation in patients which may otherwise be treated non-operatively [16].

There have been concerns over the use of incisional infiltration. It was suggested that infiltration with local anaesthetics might increase the risk of postoperative wound infection. This concern has not been substantiated by clinical studies and it appears that local anaesthetics, particularly bupivacaine, may have both bacteriostatic and bactericidal actions [17].

Further concerns have been raised as local anaesthetics may have a local toxic effect and delay wound healing. Under laboratory conditions, both myotoxicity and chondrotoxicity have been demonstrated with large doses of local anaesthetics. However, this effect has not been established in humans [17].

This study is limited by the fact that patient sample is too small to champion this technique. The lower risks involved with local anaesthesia (LA) toxicity despite the use of a very low concentration for infiltration still includes anaphylaxis, LA toxicity or failure and tachycardia leading to myocardial ischaemia.

\section{Conclusion}

Infiltration anaesthesia has long been described in major orthopaedic surgery [10] [11] [17]. This record by Augustine et al. in 1955 described the technique, essentially to progressively flood the surgical site with dilute solution of anaesthetic agent allowing surgery for up to 4 hours. Infiltration of local anaesthetic at the site of surgical incision offers a rational approach to perioperative analgesia. Unfortunately, due to the unfavourable 
pharmacokinetics of local anaesthetics, this technique is limited by a short duration of action. This method presents itself as an option in managing patient with high comorbidities. It decreases the risk of deep vein thrombosis, pulmonary embolism, myocardial infarction, pneumonia and postoperative confusion associated with general anaesthetic and helps reduce operative delays.

\section{References}

[1] Indelli, P.F., et al. (2005) Regional Anesthesia in Hip Surgery. Clinical Orthopaedics and Related Research, 441, 250-255. http://dx.doi.org/10.1097/01.blo.0000192355.71966.8e

[2] Sorenson, R.M. and Pace, N.L. (1992) Anesthetic Techniques during Surgical Repair of Femoral Neck Fractures. A Meta-Analysis. Anesthesiology, 77, 1095-1104. http://dx.doi.org/10.1097/00000542-199212000-00009

[3] Luger, T.J., et al. (2010) Neuroaxial Versus General Anaesthesia in Geriatric Patients for Hip Fracture Surgery: Does It Matter? Osteoporosis International, 21, S555-S572. http://dx.doi.org/10.1007/s00198-010-1399-7

[4] Urwin, S.C., Parker, M.J. and Griffiths, R. (2000) General Versus Regional Anaesthesia for Hip Fracture Surgery: A Meta-Analysis of Randomized Trials. British Journal of Anaesthesia, 84, 450-455. http://dx.doi.org/10.1093/oxfordjournals.bja.a013468

[5] Parker, M.J., Handoll, H.H. and Griffiths, R. (2001) Anaesthesia for Hip Fracture Surgery in Adults. Cochrane Database of Systematic Reviews, 2001, Article ID: CD000521.

[6] Finlayson, B.J. and Underhill, T.J. (1988) Femoral Nerve Block for Analgesia in Fractures of the Femoral Neck. Archives of Emergency Medicine, 5, 173-176. http://dx.doi.org/10.1136/emj.5.3.173

[7] Howard, C.B., et al. (1983) Forum. Femoral Neck Surgery Using a Local Anaesthetic Technique. Anaesthesia, 38, 993-994. http://dx.doi.org/10.1111/j.1365-2044.1983.tb12032.x

[8] Fletcher, A.K., Rigby, A.S. and Heyes, F.L. (2003) Three-in-One Femoral Nerve Block as Analgesia for Fractured Neck of Femur in the Emergency Department: A Randomized, Controlled Trial. Annals of Emergency Medicine, 41, 227-233. http://dx.doi.org/10.1067/mem.2003.51

[9] McGlone, R., et al. (1987) Femoral Nerve Block in the Initial Management of Femoral Shaft Fractures. Annals of Emergency Medicine, 4, 163-168. http://dx.doi.org/10.1136/emj.4.3.163

[10] Berry, F.R. (1977) Analgesia in Patients with Fractured Shaft of Femur. Anaesthesia, 32, 576-577. http://dx.doi.org/10.1111/j.1365-2044.1977.tb10009.x

[11] Haddad, F.S. and Williams, R.L. (1995) Femoral Nerve Block in Extracapsular Femoral Neck Fractures. Journal of Bone and Joint Surgery, 77, 922-923.

[12] Vloka, J.D., et al. (1999) Anatomical Landmarks for Femoral Nerve Block: A Comparison of Four Needle Insertion Sites. Anesthesia Analgesia, 89, 1467-1470.

[13] McAuliffe, N. and Harmon, D. (2009) Ultrasound-Guided Hematoma Block in Fractured Neck of Femur. Regional Anesthesia and Pain Medicine, 34, 80-81. http://dx.doi.org/10.1097/AAP.0b013e3181933ff9

[14] Sher, D. and Biant, L.C. (2007) Subcapital Fracture of the Femoral Neck in Medically Unwell Patients: Technique for Fixation Using Direct Infiltration Local Anaesthetic Rather than Regional Blockade. Injury, 38, 1209-1213. http://dx.doi.org/10.1016/j.injury.2007.04.024

[15] Augustine, R.W., Macausland Jr., W.R. and Greenwald, W.F. (1955) Local Infiltration Anaesthesia for Knee-Joint Surgery. Journal of Bone and Joint Surgery, 37, 855-858.

[16] Scott, N.B. (2010) Wound Infiltration for Surgery. Anaesthesia, 65, 67-75. http://dx.doi.org/10.1111/j.1365-2044.2010.06241.x

[17] Brower, M.C. and Johnson, M.E. (2003) Adverse Effects of Local Anaesthetic Infiltration on Wound Healing. Regional Anesthesia and Pain Medicine, 28, 233-240. http://dx.doi.org/10.1097/00115550-200305000-00011 
Scientific Research Publishing (SCIRP) is one of the largest Open Access journal publishers. It is currently publishing more than 200 open access, online, peer-reviewed journals covering a wide range of academic disciplines. SCIRP serves the worldwide academic communities and contributes to the progress and application of science with its publication.

Other selected journals from SCIRP are listed as below. Submit your manuscript to us via either submit@scirp.org or Online Submission Portal.
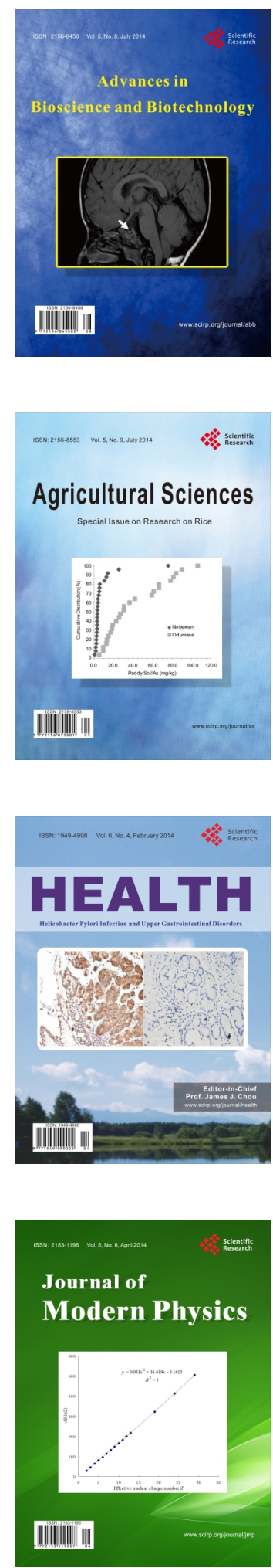
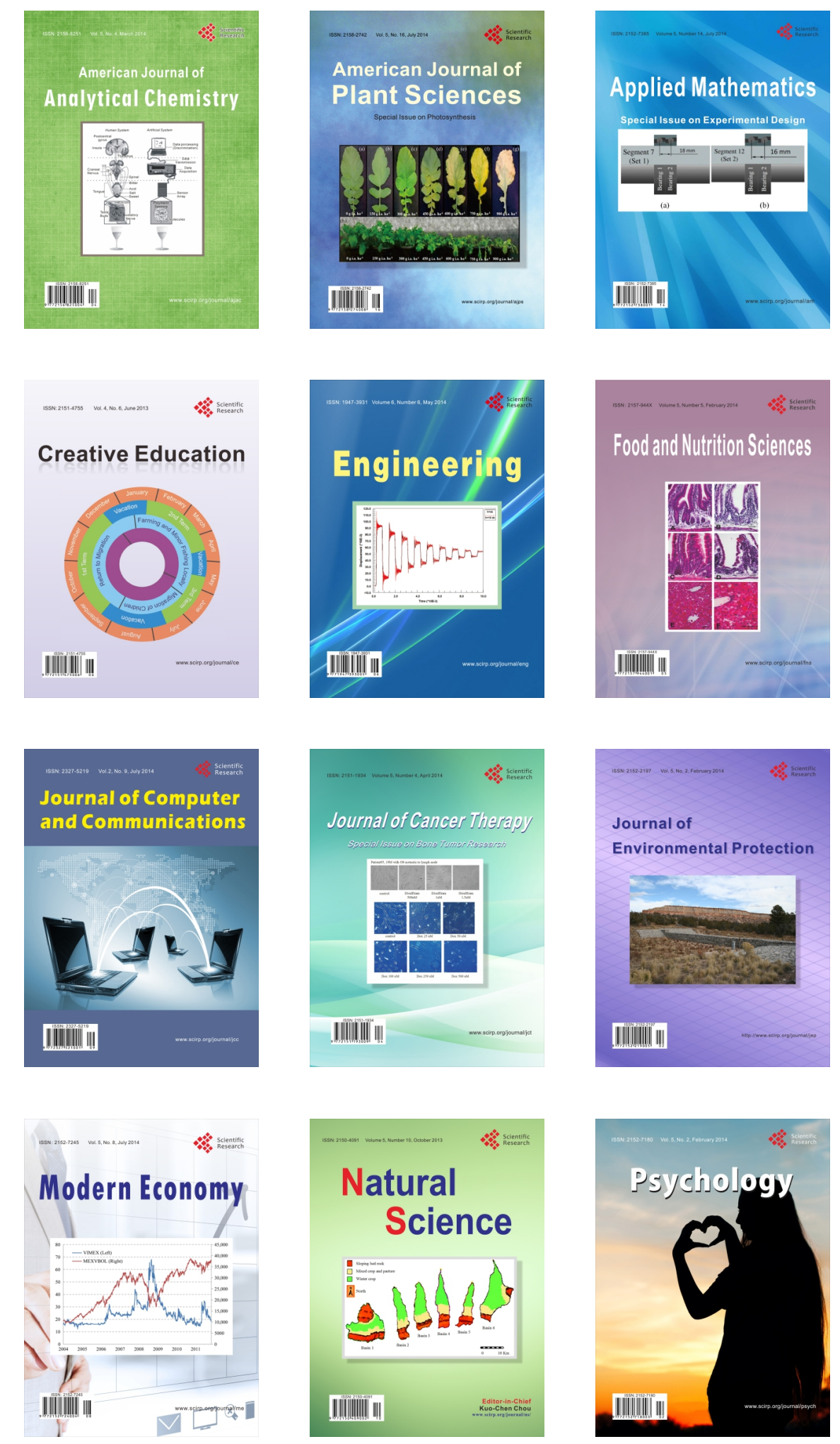